
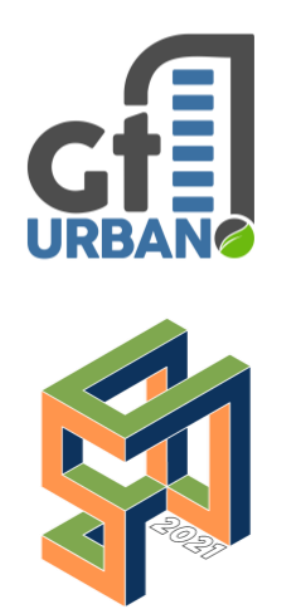

\section{SINGEURB}

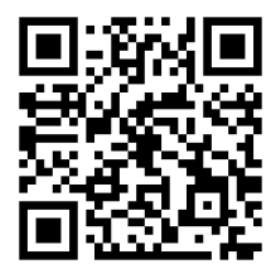

Como citar:

LOPES, Bruna L. V.; TEIXEIRA, Bernardo A. N. Proposição de variáveis para avaliação do uso de técnicas compensatórias no manejo de águas pluviais em áreas já urbanizadas. In: III SIMPÓSIO NACIONAL DE GESTÃO E ENGENHARIA URBANA: SINGEURB, 2021, Maceió. Anais... Porto Alegre: ANTAC, 2021. p. 202-208.

Disponível em: https://eventos.antac.o rg.br/index.php/singe urb/issue/view/14

\title{
Proposição de variáveis para avaliação do uso de técnicas compensatórias no manejo de águas pluviais em áreas já urbanizadas
}

\author{
Proposal of variables for evaluation of the use of \\ compensatory techniques in Rainwater \\ management in already urbanized areas
}

Bruna L. V. Lopes, Universidade Federal de São Carlos, bruna.lamorea@hotmail.com

Bernardo A. N. Teixeira, Universidade Federal de São Carlos, bernardo@ufscar.br

\section{RESUMO}

Com o crescimento das áreas urbanas, são gerados problemas de manejo das águas pluviais decorrentes da impermeabilização do solo, agravados pelo uso de técnicas de drenagem que não lidam adequadamente com a questão. As Técnicas Compensatórias (TC) surgiram como alternativa para aproximar o ciclo das águas pluviais urbanas dos ciclos naturais. Entretanto, o emprego das TC é muitas vezes associado a situações em que a urbanização ainda será feita, desconsiderando as áreas já urbanizadas. Neste sentido, é necessária a verificação dos limites e potencialidades da aplicação das TC neste último caso. Assim, o presente artigo tem como objetivo propor variáveis que devem ser consideradas na tomada de decisão da escolha de TC em áreas já urbanizadas. Para isto, foram identificadas na literatura variáveis que devem ser consideradas para a escolha e a implantação de TC. Novas variáveis especificamente relacionadas às áreas já urbanizadas foram acrescentadas e a sistematização final resultando num conjunto que pode vir a ser empregado nestas áreas. Deste modo, é possível conclui que, embora algumas preocupações adicionais devam ser consideradas, há possibilidades reais do emprego das TC nas áreas já urbanizadas.

Palavras-chave: Drenagem Urbana, Técnicas Compensatórias, Urbanização.

\section{ABSTRACT \\ With the growth of urban areas, the problems are result of waterproofing in the soil, aggravated by the use of drainage techniques that do not adequately deal with the issue. The called Compensatory Techniques (CT) appeared as an alternative to bring the cycle of urban rainwater closer to natural cycles. However, the use of CT is often associated with situations in which urbanization will be done, disregarding areas that already been urbanized. In this sense, it is necessary to check the limits and potentialities of the application of CT in the last case. So, the presente article aimed to propose variables that should be considered when deciding on the choice of CT in already urbanized areas. For this, variables were identified in the literature that should be considered for the choice and implantation of CT. New variables}


specificalt related to the already urbanized areas were added and the final systematization resulted in a set that may be used in these areas. It was concluded that, although some additional concerns must be considered there are real possibilities for the use of CT in already urbanized areas.

Keywords: Urban drainage, Compensatory techniques, Urbanization.

\section{INTRODUÇÃO}

Com a expansão das cidades, ocorrem diversos impactos, dentre os quais a impermeabilização do solo, acarretando problemas devido à dificuldade de infiltração das águas pluviais escoadas. $\mathrm{O}$ sistema convencional de drenagem, vem demonstrando crescente ineficiência, por não conseguir atender às vazões do escoamento superficial ou por transferir os efeitos de cheias para jusante. Para compensar tal ineficiência, busca-se uma compreensão mais integrada da área urbana e dos ciclos naturais, contemplando relações entre os sistemas tecnológicos, legais e sociais para a concepção e implantação dos sistemas de drenagem urbana (PORTO et al, 2015).

Desde meados da década de 1970, estão sendo desenvolvidas Técnicas Compensatórias (TC) de drenagem em diferentes concepções, com a intenção de minimizar os impactos da urbanização sobre os processos hidrológicos, valorizando a presença da água no ambiente urbano e, sendo prevista a integração urbanística destas técnicas, com a criação de espaços de convivência e contemplação para a população, buscando a preservação dos recursos naturais envolvidos (BAPTISTA et al, 2015).

Além de solucionar problemas relacionados a picos de vazão, volumes escoados e não infiltrados, arraste de poluentes e contaminantes, entre outros. as TC têm sido propostas e adotadas como soluções hidrológicas que permitem integrar os meios hídrico, ecológico e urbano, podendo também melhorar a estética urbana e possibilitar usos multifuncionais (TUCCI, 2015).

Para auxiliar na escolha e na implantação das diferentes tipologias de TC, são normalmente consideradas variáveis características de cada uma delas e do contexto de aplicação. Nem sempre, entretanto, tais variáveis consideram a áreas já urbanizadas com suas características mais restritivas. É interessante, assim, identificar estas limitações, mas também as potencialidades do uso das TC neste contexto, contemplando variáveis mais adequadas.

Sendo assim, esse trabalho teve o objetivo de identificar e sistematizar, a partir da literatura existente e de novas proposições, variáveis a serem consideradas para a definição do emprego de Técnicas Compensatórias (TC) na gestão de águas pluviais em áreas já urbanizadas.

\section{MÉTODO DE PESQUISA}

Com a bibliografia revisada, foi possível encontrar características fundamentais que precisam ser observadas antes da implantação de TC, seja em um meio em urbanização, já urbanizado ou objeto de reurbanização. Foram consultadas publicações de autores especialistas no assunto, com abordagens conceituais sobre as TC, bem como manuais técnicos adotados tanto em cidades brasileiras, como de outros países (BAPTISTA ET al., 2015; BRASÍLIA, 2018, CANHOLI, 2005; CITY AND COUNTRY OF DENVER, 2013; CITY OF PORTLAND, 2016; CITY OF TORONTO, 2006; CURITIBA, 2002; EASTON WASHINGTON, 
No presente trabalho, as TC que foram analisadas para a criação das variáveis foram: Bacias de Retenção/Detenção; Jardins de Chuva; Trincheiras de Infiltração; Valas e Valetas de Infiltração; Pavimentos Permeáveis; Faixas Gramadas; Poços de Infiltração; Telhados de Cobertura Vegetal; Reservatórios Individuais.

A partir da identificação das variáveis que precisam ser consideradas, foi possível encontrar as principais condições a serem observadas antes da implantação das TC, sendo possível criar uma listagem facilitadora para ajudar na escolha de TC mais apropriada para diversos tipos de situação.

Além das variáveis identificadas a partir da bibliografia, também foi necessário adotar, a partir da observação de contextos já urbanizados e suas possíveis interferências, algumas novas variáveis que não haviam sido previamente identificadas,

Por fim, após a sistematização das variáveis encontradas na literatura e a inclusão das novas variáveis sugeridas, foram selecionadas aquelas aplicáveis ao contexto de um meio urbano já consolidado. Para tanto, foram consideradas especificidades como: indisponibilidade de áreas, ocupação prévia, infraestruturas existentes, impactos socioeconômicos, aceitação da comunidade, impactos da realização de obras.

\section{IDENTIFICAÇÃO DE VARIÁVEIS EM PUBLICAÇÕES}

A partir da análise das TC encontradas na bibliografia foi possível identificar os aspectos importantes a serem destacados para a implantação de TC, assim, sendo possível separar em 3 grupos de variáveis: 1) Aspectos Quantitativos; 2) Aspectos Qualitativos; 3) Aspectos Sociais, Econômicos e Operacionais.

A maioria das variáveis foi encontrada com os mesmos nomes ou nomes similares na bibliografia, sendo citadas de acordo com os autores. Em alguns casos, os nomes eram diferentes, mas em função da descrição apresentada, foi possível adotar identificação e denominação únicas.

\subsection{Aspectos quantitativos}

Os aspectos quantitativos são aqueles relacionados a valores de quantidades, seja da água manejada, seja de características do meio físico e do entorno, listados a seguir:

- Declividade do Terreno

-Declividade de Cobertura

- Capacidade de Infiltração do Solo

-Profundidade do Lençol Freático

- Área da Bacia de Contribuição

- Área Superficial Ocupada pela TC

-Ausência de Exutório Superficial

- Flexibilidade de Projeto

- Fragilidade do Solo por Ação da Água

- Esforços e Vibrações Externas

- Tipo de Circulação de Veículos 
-Interferência com Instalações Subterrâneas

-Possibilidade de Integração com o Sistema de Drenagem Existente

Os aspectos quantitativos dizem respeito a situações de vazões, volumes, proporções, quantificações e possibilidades de interferências físicas ou interligações com sistemas existentes, trazendo uma relação com aspectos que precisam ser analisados como área, profundidade, fragilidade do solo, construções já existentes, dentre outras.

\subsection{Aspectos qualitativos}

Consideram-se aqui como aspectos qualitativos aqueles relacionados com a qualidade da água pluvial e a presença de poluentes ou contaminantes, que interferem na implantação, operação ou eficiência da TC, a saber:

- Carga Poluidora de Afluentes à TC

- Taxa de Sedimentos Afluentes à TC

- Resíduos Sólidos afluentes à TC

- Risco Sanitário Associado a Operação e Manutenção

- Risco Sedimentológico Associado a Operação e Manutenção

- Contaminação de Aquífero

-Proliferação de Vetores

Aspectos qualitativos trazem os critérios de avaliação sobre a qualidade da água que chegará até o corpo receptor, prevendo possíveis problemas nesse percurso, como poluições diversas, causadas por resíduos sólidos, falta de manutenção ou manutenção inadequada e contaminação do aquífero existente na região.

\subsection{Aspectos sociais, econômicos e operacionais}

Foram incluídos nos aspectos gerais aqueles relacionados a situações variadas que afetam de alguma forma a implantação e funcionamento das TC. São eles:

-Intensidade e Tipo de Manutenção

- Possibilidade de Implantação em Áreas Privadas

- Disponibilidade de Áreas Públicas

-Interferência das Obras de Implantação com Atividades Existentes

- Aceitação pela População

- Possibilidade de Incentivos

-Uso de Áreas de Circulação e Estacionamento de Veículos

- Tipologia de Uso e Ocupação do Solo

-Possibilidade de Composição Paisagística

-Possibilidade de Usos Múltiplos

- Custo de Implantação

• Custo de Operação e Manutenção

Os aspectos sociais, econômicos e operacionais são aqueles que englobam problemas relacionados à população local, aos órgãos públicos, às áreas privadas, aos custos e às necessidades de operação e 
manutenção das TC. No geral, são aspectos que pesam sobre o custo-benefício para um segundo olhar antes da implantação, após da sua primeira necessidade que seria a da drenagem de água pluvial.

\subsection{Proposição de novas variáveis para áreas já urbanizadas}

A partir da listagem das variáveis de diferentes aspectos encontradas na bibliografia, foi preciso também analisar quais outras características são necessárias a serem avaliadas para a implantação de uma TC, em especial numa área já urbanizada. Assim, foi possível considerar outras variáveis que não foram identificadas na bibliografia e que são listadas a seguir:

-Necessidade de Áreas Superficiais Contínuas

-Possibilidade de Reurbanização da Área

- Possibilidade de Fraudes ou Usos Indevidos

-Dispersão dos Lançamentos em Diferentes Pontos dos Corpos Receptores

- Tipo de Cobertura das Edificações

As variáveis foram propostas observando-se situações que podem ocorrer numa área já urbanizada, decorrente da presença de pessoas, edificações, vias de circulação, sistemas de infraestrutura (inclusive a drenagem pluvial), atividades econômicas existentes, entre outras, prevendo-se possíveis problemas ou facilidades a serem considerados antes da implantação de uma TC. Acredita-se que, para situações específicas, algumas destas variáveis não se aplicam, enquanto em outros casos poderão surgir novas variáveis.

\section{SISTEMATIZAÇÃO FINAL DE VARIÁVEIS PARA ÁREAS JÁ URBANIZADAS}

Como resultado das etapas anteriores, foram consideradas variáveis específicas para áreas já urbanizadas, que são apresentadas no Quadro 1.

Quadro 1 - Variáveis Propostas para Aplicação de TC em Áreas já Urbanizadas

VARIÁVEIS PROPOSTAS PARA A APLICAÇÃO DE TC EM ÁREAS JÁ URBANIZADAS
Área Superficial Ocupada pela TC
Necessidade de Áreas Superficiais Contínuas
Esforços e Vibrações Externas
Interferência com Instalações Subterrâneas
Possibilidade de Integração com o Sistema de Drenagem Existente
Possibilidade de Implantação em Áreas Privadas
Disponibilidade de Áreas Públicas
Interferência das Obras de Implantação com as Atividades Existentes




\begin{tabular}{|c|}
\hline Aceitação pela População \\
\hline Uso de Áreas de Circulação e Estacionamento de Veículos \\
\hline Possibilidade de Usos Múltiplos \\
\hline Possibilidade de Reurbanização da Área \\
\hline Possibilidade de Fraudes ou Usos Indevidos \\
\hline Dispersão dos Lançamentos em Diferentes Pontos dos Corpos Receptores \\
\hline
\end{tabular}

Fonte: Os autores

A necessidade de grandes áreas, muitas vezes, torna a implantação de uma TC inviável para algumas cidades, por não possuírem disponibilidade de espaço suficiente. Algumas TC como as bacias, necessitam de grandes espaços para sua implantação. Sendo assim, locais com alta densidade de urbanização, consequentemente não possuem disponibilidade de grandes áreas, necessitando muitas vezes a avaliação de uma possível implantação da TC utilizando espaços menores, mas localizada em mais do que apenas em um local da área escolhida.

Algumas TC, principalmente as de infiltração como trincheiras e valas, não são feitas com materiais de extrema durabilidade para serem implantadas em locais com tráfegos intensos ou que precisem suportar grandes cargas ou vibrações.

Para a implantação de TC que apresente elementos abaixo do nível do solo ou que trabalhem com a infiltração da água pluvial é necessário observar se ocorrerão interferências com instalações subterrâneas, com fundações ou com outras estruturas enterradas já existentes.

As variáveis definidas para a aplicação em um meio já urbanizado também podem ser utilizas em quaisquer situações, mas elas acabam se referindo a locais com infraestruturas existentes e com falta de disponibilidade de espaço, que são características da urbanização. De modo geral, os maiores problemas encontrados para a implantação de TC em áreas já urbanizadas são a falta de espaços ou a dificuldade de integração com estruturas existentes, como parques e estacionamentos.

\section{CONCLUSÕES}

A implantação de TC é algo que remete a um novo paradigma de manejo de águas pluviais, contemplando maior integração com o meio ambiente, e é relativamente mais fácil em urbanizações a serem implantadas. Assim, muitas vezes as TC não são devidamente consideradas em contextos já urbanizados, reduzindo sua aplicabilidade. Entretanto, avaliação específica de cada local pode ajudar a superar esta possível limitação.

A sistematização de variáveis especificamente selecionadas para um meio já urbanizado, como apresentada no presente trabalho, pode contribuir para que aspectos limitadores e potencializadores das diferentes TC possam ser melhor conhecidos e considerados. O desenvolvimento de um método com base nas variáveis é uma etapa subseqüente desta pesquisa, buscando ampliar o alcance da utilização das TC mesmo em áreas já urbanizadas. 


\section{AGRADECIMENTOS}

À Coordenação de Aperfeiçoamento de Pessoal Nível Superior (CAPES) pela concessão de bolsa de estudo de Mestrado (Código de Financiamento 001).

\section{REFERÊNCIAS}

BAPTISTA, M. B.; NASCIMENTO, N. O.; BARRAUD, S. Técnicas Compensatórias em Drenagem Urbana. 2 edição. Associação Brasileira de Recursos Hídricos (ABRH), 2015.

BRASÍLIA - MANUAL DE DRENAGEM E MANEJO DE ÁGUAS PLUVIAIS URBANAS DO DISTRITO FEDERAL. Superintendência de Drenagem Urbana: Brasília, 2018.

CANHOLI, A. P. Drenagem Urbana e Controle de Enchentes. São Paulo: Oficina de Textos, 2005. CITY AND COUNTRY OF DENVER - Storm Drainage Design \& Techinical Criteria, 2013.

CITY OF PORTLAND - Stormwater Management Manual, 2016.

CITY OF TORONTO - Wet Weather Flow Management, 2006.

CURITIBA - PLANO DIRETOR DE DRENAGEM PARA BACIA DO RIO IGUAÇU NA REGIÃO METROPOLITANA DE CURITIBA. Programa de Saneamento Ambiental da Região Metropolitana de Curitiba: Região Metropolitana de Curitiba. PR, 2002.

EASTON WASHINGTON - Low Impact Development Guidance Manual. Departament of Ecology State of Washington, 2013.

GOBIERNO DE MADRID - Guía Básica de Deseño de Sistemas de Gestión Sostenible de Aguas Pluviales em Zonas Verdes y otros Espacios Libres. Madrid, 2018.

GOBIERNO DE ESPAÑA - Guías de Adaptación al Riesgo de Inundacíon: Sistemas Urbanos de Drenagem Sostenible. Ministerio para la Transición Ecológica. Gobierno de España, 2019.

MARYLAND - Low-Impact Development: Na Integrated Environmental Design Approach. Department of Environmental Resources, Programs and Planning Divison. Price's Contry - Maryland, 1999.

PORTO, Rubem; ZAHED FILHO, Kamel; TUCCI, Carlos; BIDONE, Francisco. Drenagem Urbana. In: TUCCI, C. E. M.; SILVEIRA, A. L. L.;... [et al]. Hidrologia: ciência e aplicação. 4 ed. - Porto Alegre: Editora da UFRGS/ABRH. 2015.

SÃO PAULO - MANUAL DE DRENAGEM E MANEJO DE ÁGUAS PLUVIAIS. Secretaria Municipal de Desenvolvimento Urbano: São Paulo - SP, 2012.

TUCCI, C. E. M. Inundações Urbanas. In: TUCCI, C. E. M.; PORTO, R. La L.; BASTOS, M. T. Drenagem Urbana. Porto Alegre: ABRH, 2015. 